\title{
Dissemination of the resistant forms of intestinal worms in the marshy areas of the city of Yaounde (Cameroon): importance of some abiotic factors of the medium
}

\author{
Ajeagah Gideon Aghaindum ${ }^{1} \cdot$ Fotseu Kouam Arnold Landry ${ }^{1}$
}

Received: 5 December 2017 / Accepted: 9 January 2019 / Published online: 18 January 2019

(C) The Author(s) 2019

\begin{abstract}
A study was undertaken from January to June 2016 with the aim of characterizing the environmental forms of intestinal helminths that are present in some marshy areas in Yaounde. Monthly water samplings were carried out on eight different marshy areas which are: Bonamoussadi, Melen, Etoug-ebe, Mvog-betsi, Mokolo-elobie, Tsinga, Ekounou and Damas in the city of Yaounde. The observation of eggs and larvae of helminths was done using an inverted Olympus CK2 microscope with objective 40, after concentration of the samples, following the formol-ether concentration and/or Kato-Katz techniques. The hydrological and physicochemical assessment of the samples reveals a low oxygenation $(20.93 \pm 9.83 \%)$ and a high mineralization $(566.16 \pm 119.91 \mu \mathrm{S} / \mathrm{cm})$ of these ecosystems. The biological analysis reveals the presence of eggs belonging to Ascaris sp., Enterobius sp., Ankylostomes sp., Trichostrongylus sp., Trichuris sp., Teenia sp., Hymenolepis nana, Hymenolepis diminuta, Diphyllobothrium sp., Fasciola sp., Schistosoma sp. and the larvae of Strongyloïdes sp. The statistical analysis presents a significant correlations to the threshold of 5\% and $1 \%$ between the physicochemical and biological parameters quantified in our study.
\end{abstract}

Keywords Abundance dynamics $\cdot$ Helminths resistance forms $\cdot$ Marshy areas

\section{Introduction}

Parasitic infections represent more than $40 \%$ of the morbid load of tropical diseases in the world (Youssef and Driss 2007). Africa shares this situation in the intertropical belt, which constitutes a predirection for parasitic infections. Among these diseases, helminthiasis occupies a considerable position in tropical Africa. It affects more than 2 billion people in the world, among whom 300 million present serious infections and 155,000 deaths are exposed to their direct or indirect effect each year (WHO 1999). In Cameroon, helminthiases are part of the most chronic parasitic diseases (Tchuem Tchuemté et al. 2001). Epidemiological surveys carried out gave some indications on the prevalence

Ajeagah Gideon Aghaindum

ajeagahg@yahoo.com

Fotseu Kouam Arnold Landry

arnoldfotseu@yahoo.com

1 Laboratory of Hydrobiology and Environment, University of Yaounde 1, Yaoundé, Cameroon of the most frequent worms. More than 7 million people are infested by trichocephalosis, 6 million by ascaridiasis and 2 million by ankylostomiasis in tropical Africa. In spite of these observations, helminthiases nowadays have little interest besides diseases like the acquired immune deficiency syndrome (AIDS), tuberculosis and malaria (PNLSHI 2010).

The town of Yaounde has a high level of urbanization, and the access to good quality water still remains an expectation for the inhabitants. This water deficit imposes on the population to reuse water flowing through the marshy areas in agriculture (Kengne et al. 2002). This has the advantage of enriching the irrigated soils and plants with nutrients such as nitrates and phosphates. The issuing wastewater is a potential source of viral, bacterial and parasitic contamination (Youssef and Driss 2007). The present aims of this study are isolating and identifying the various forms of resistance of intestinal helminths that are present in the marshy areas in Yaounde and assessing the role played by environmental factors for their dissemination. 


\section{Materials and methods}

\section{Map of the sampling stations}

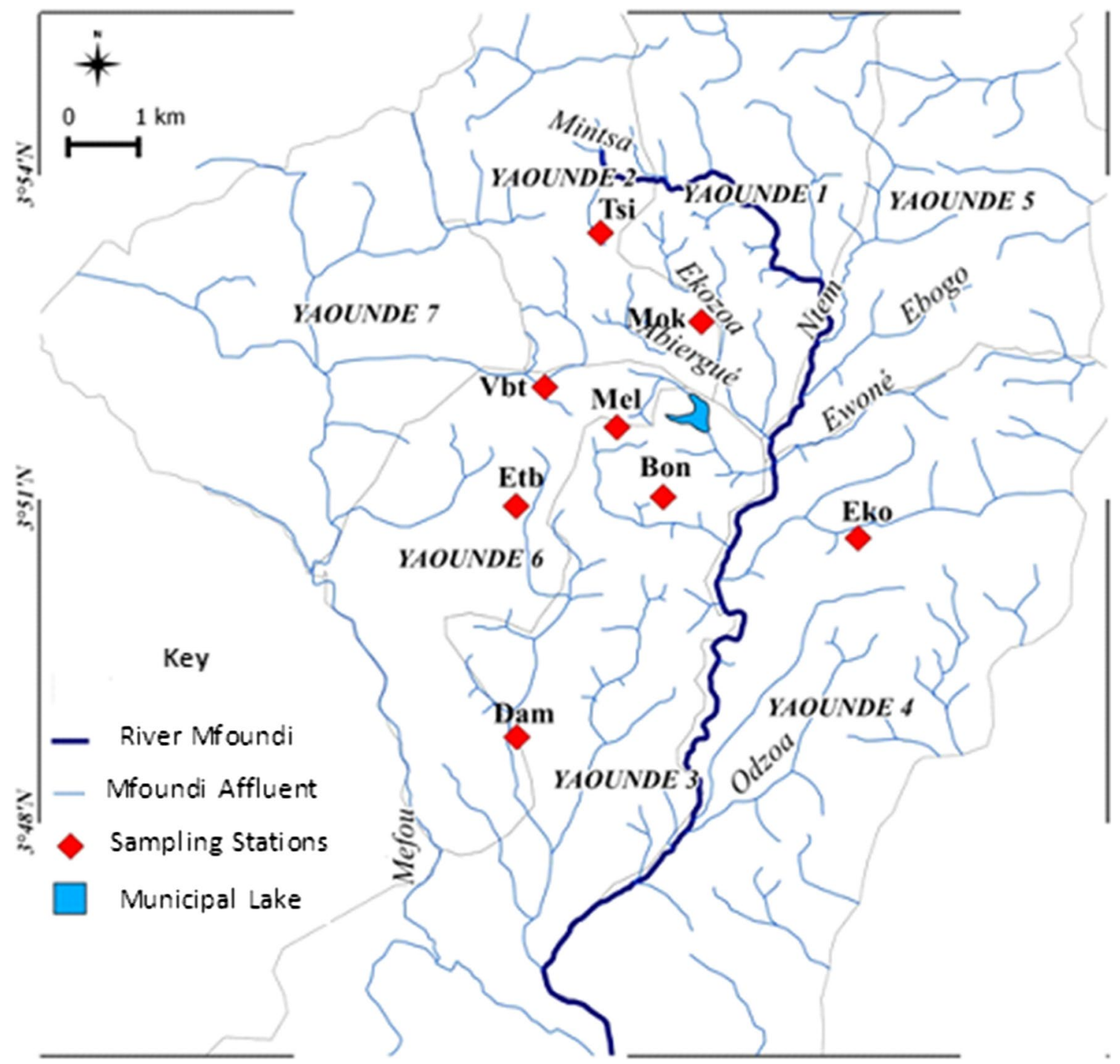

Mok $=$ mokolo $; \mathbf{T s i}=$ Tsinga $; \mathbf{V b t}=$ Mvog-betsi $; \mathbf{M e l}=$ Melen $; \mathbf{E t b}=$ Etoug-ebe $;$

Bon $=$ Bonamoussadi $; \mathbf{E k o}=$ Ekounou $;$ Dam $=$ Damas

\section{Period of study}

The study was carried out from January to June 2016, in eight marshy zones (Bonamoussadi, Melen, Mvog-betsi, Etoug-ebe, Mokolo, Tsinga, Ekounou and Damas) of Capital city of Yaounde. Physicochemical and biological analyses were carried out on water samples taken from these stations following a monthly frequency. The monthly data obtained were then grouped according to the long dry season (LDS) and the short rainy season (SRS).
The physicochemical analyses were carried out following the recommendations of Rodier (2009). The water samples were taken using the adapted bottles with double closing system of 250 and $1000 \mathrm{~mL}$ and then preserved and transported in a cooled flask for analysis in the laboratory of Hydrobiology and Environment of the University of Yaounde I. Temperature was measured by the electronic thermometer. Dissolved oxygen content was carried out by the volumetric method of Winkler, and oxydability was done by titration. The evaluation of electric conductivity was done by multimeter model 
HANA HI 9829. Suspended matter was measured in the laboratory by colorimetry using a spectrophotometer DR/3900. Orthophosphates, ammoniacal nitrogen and nitrates were quantified by colorimetry by spectrophotometer DR/3900 using reagents such as NitraVer for nitrate and PhosVer for orthophosphate.

\section{Biological analyses}

The sampling for the identification of helminths eggs and larvae was carried out in each station on the sampling points that are characterized by an accumulation of organic matter and the presence of macrophytes in the water banks. After a slight agitation, to put the suspended particles into the column, water was immediately taken using sterile polyethylene bottles of $1 \mathrm{~L}$ and was fixed with formalin $10 \%$ and then transported to the laboratory of Hydrobiology and Environment of the University of Yaounde I. These samples were left to rest at ambient temperature for $24 \mathrm{~h}$ period to allow the process of sedimentation; then, the supernatant was poured, and the volume of the sediment base collected was measured. The Kato-Katz and formol-ether concentration techniques enabled us to concentrate the parasitic elements in order to guarantee a better enumeration. The observation of eggs and larvae of helminths was done under an inverted microscope of mark Olympus CK2, with objectif 40 and identified using WHO keys for identification (WHO 1994). The dimensions were measured by the ocular micrometer of the optical microscope.

The number of parasitic helminths eggs $(X)$ in $1 \mathrm{~L}$ of sample can be obtained by the following formula (Ajeagah et al. 2014):

$\frac{X=y \cdot V x}{V y}\left[\begin{array}{l}V x=\text { volume of the base in } 1 \mathrm{~L} \text { of sample } \\ V y=\text { volume of the base used for observation } \\ y=\text { number of eggs observed in } V y\end{array}\right.$

The statistical analyses were carried out using the software SPSS 17.0 with Kruskal-Wallis, associated with Mann-Whitney test and the correlations of Spearman, while the principal components analysis was carried out with the assistance of XLSTAT software.

\section{Results and discussion}

\section{Results}

\section{Spatiotemporal variation of the physicochemical parameters}

Temperature and suspended solids The average temperature varies from $24.66 \pm 0.23{ }^{\circ} \mathrm{C}$ in SRS at Damas to $28.86 \pm 1.05{ }^{\circ} \mathrm{C}$ obtained in LDS at Ekounou. These values present an average of $26.61 \pm 0.39^{\circ} \mathrm{C}$ (Fig. 1a). Apart from Bonamoussadi and Ekounou, all the other sampling points showed higher values during the LDS. None of these variations of the physicochemical parameters were significant to the threshold value of $5 \%(p=0.1097)$. The measurement of suspended matter content shows that apart from the Ekounou station, the highest values are observed in LDS (Fig. 1b). The maximum value is observed at the Mvogbetsi station $(51.66 \pm 15.30 \mathrm{mg} / \mathrm{L})$ in the LDS and the minimal value at the Ekounou station $(12 \pm 7 \mathrm{mg} / \mathrm{L})$ in the SRS with an average of $23.37 \pm 5.41 \mathrm{mg} / \mathrm{L}$. No significant difference is observed between the stations and the seasons at the threshold of $5 \%(p=0.650)$ in the studying areas.

Percentage of saturation of oxygen, oxydability, electric conductivity and orthophosphate The values for the percentage of saturation of oxygen obtained in SRS are higher than those obtained in LDS. The minimal value of $6.62 \pm 4.55 \%$ was obtained at Etoug-ebe in LDS, and the maximum value of $39.1 \pm 3.53 \%$ was obtained at the Melen in SRS (Fig. 2a). These values oscillate around an average value of $20.93 \pm 9.83 \%$. The difference between the results obtained for this parameter is not significant both on the seasonal $(p=0.84)$ and spatial level. The values for oxydability vary from $1.575 \pm 0.195 \mathrm{mg} / \mathrm{L}$ of $\mathrm{KMnO}_{4}$ (Melen, LDS) to $22.77 \pm 19.72 \mathrm{mg} / \mathrm{L}$ of $\mathrm{KMnO}_{4}$ (Mokolo, LDS) (Fig. 2b). No significant difference was observed on the seasonal level $(p=0.1946)$, but on the spatiotemporal, a significant difference between the Mokolo and all the other stations $(p=0.03704)$ was evaluated.

The values of conductivity were higher in LDS with a maximum of $1080.33 \pm 303.2 \mu \mathrm{S} / \mathrm{cm}$ (Mvog-betsi, LDS) and a minimum of $220 \pm 38.1 \mu \mathrm{S} / \mathrm{cm}$ (Ekounou, SRS)
Fig. 1 Spatiotemporal variation of the temperatures (a) and suspended matter (b)
A

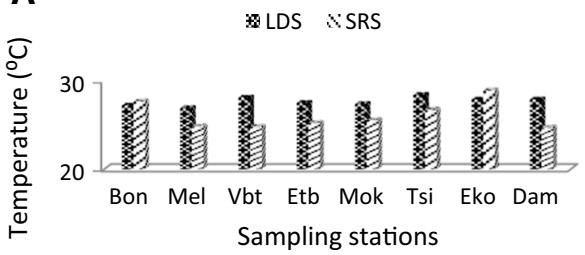

B

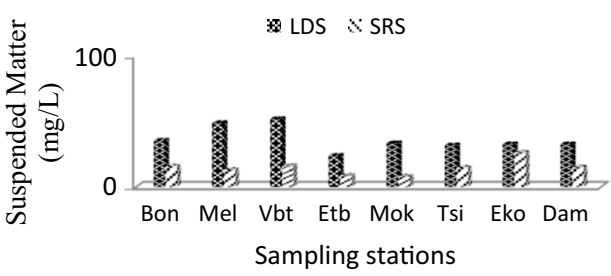


Fig. 2 Spatiotemporal variation of averages of percentage of saturation of oxygen (a), oxydability (b), electric conductivity (c) and orthophosphate (d)
A
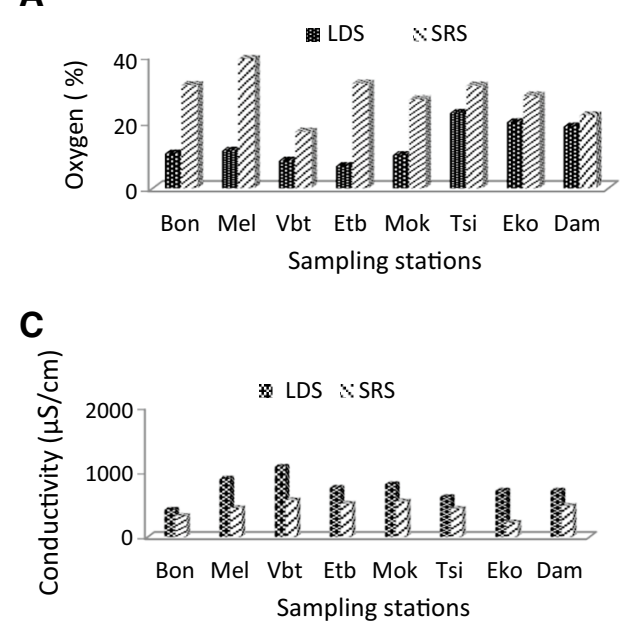

A

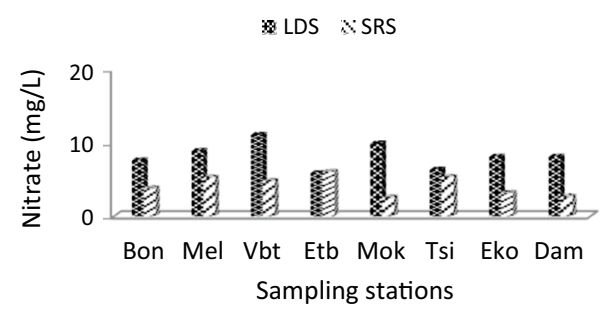

B

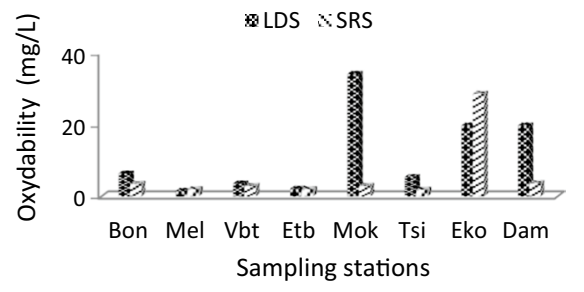

D

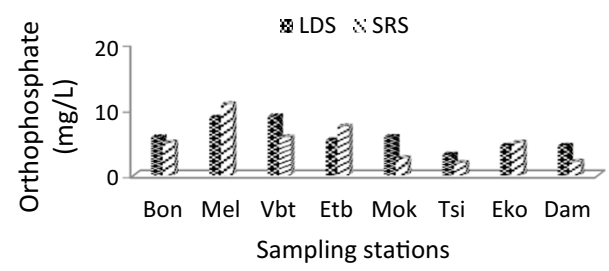

Fig. 3 Spatiotemporal variation of averages of nitrate (a), ammoniacal nitrogen (b)
(Fig. 2c). These values vary significantly according to the seasons and the stations $(p<0.05)$. The orthophosphates contents of the water vary from $1.93 \pm 1.43 \mathrm{mg} / \mathrm{L}$ of $\mathrm{PO}_{4}^{3-}$ at Tsinga during the SRS to $10.83 \pm 4.19 \mathrm{mg} / \mathrm{L}$ of $\mathrm{PO}_{4}^{3-}$ at Melen during the same season (Fig. 2c). These contents present an average value of $5.77 \pm 4.48 \mathrm{mg} / \mathrm{L}$ of $\mathrm{PO}_{4}^{3-}$. These parameters do not show any significant difference on the seasonal and spatiotemporal level $(p<0.05)$.

Nitrate and ammoniacal nitrogen Apart from Ekounou, the lowest nitrate contents are observed during the SRS. The lowest value $\left(2.56 \pm 3.38 \mathrm{NO}_{3}^{-} \mathrm{mg} / \mathrm{L}\right)$ is observed at Mokolo during the SRS, and the highest value $\left(11.06 \pm 3.75 \mathrm{NO}_{3}^{-} \mathrm{mg} / \mathrm{L}\right)$ is observed at Mvog-betsi station during the LDS. These values present an average of $5.489 \pm 1.606 \mathrm{NO}_{3}^{-} \mathrm{mg} / \mathrm{L}$ (Fig. 3a). The ammoniacal nitrogen contents of water are higher in LDS. The lowest value $\left(0.073 \pm 0.10 \mathrm{mg} / \mathrm{L}\right.$ of $\left.\mathrm{NH}_{4}^{+}\right)$is observed at Mokolo during the SRS, and the highest value $(0.70 \pm 0.13 \mathrm{mg} / \mathrm{L}$ of $\mathrm{NH}_{4}^{+}$) is observed at Mvog-betsi during the LDS (Fig. 3b). These values present an average value of $0.326 \pm 0.183 \mathrm{mg} / \mathrm{L}$ of $\mathrm{NH}_{4}^{+}$. Both these parameters do not show any significant relationship on the seasonal and spatial level $(p<0.05)$.

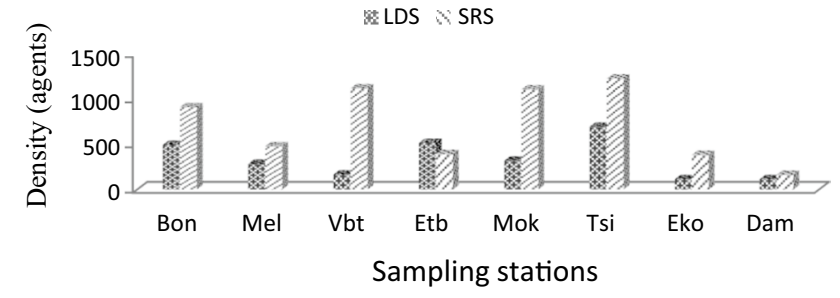

Fig. 4 Seasonal variation of the average density of eggs and the larvae of helminths

\section{Parasitological analyses}

The parasitological evaluation of the marshy areas enabled an enumeration of helminths eggs belonging to 12 species, namely Ascaris sp., Trichuris sp., Enterobius sp., Ankylostomes sp., Trichostrongylus sp., Hymenolepis nana, Hymenolepis diminuta, Tania sp. Diphyllobothrium sp., Schistosoma sp., Fasciola sp. and the larvae of Strongyloïdes sp.

Seasonal variation of the density of helminths eggs and larvae Apart from Etoug-Ebe, all the other sampling points present highest loads during the SRS. During this season, the densities vary from 1224 parasitic forms at Tsinga to 164 parasitic forms at Damas (Fig. 4). During the LDS, the highest load was also observed at Tsinga (693 agents) and 
the lowest at Ekounou and Damas (116 agents). There is no significant difference between the density of the parasitic elements identified in LDS and SRS $(p=0.246)$, and on the other hand, there exists a significant difference between the stations $(p<0.05)$ assessed.

Seasonal variation of nematode eggs: Ascaris sp. (A); Ancylostoma sp. (B); Enterobius sp. (C); Trichuris sp. (D) Trichostrongylus sp. (E) and Larvae of Strongyloïdes sp. (F) Except Damas, all the other marshy areas present the highest egg load of Ascaris sp. during the SRS. During this season, the densities vary from $215 \pm 114 \mathrm{eggs} / \mathrm{L}$ at Bonamoussadi to $8 \pm 13$ eggs/L at Damas. During the LDS, the highest load was observed at Tsinga $(78 \pm 120 \mathrm{eggs} / \mathrm{L})$ and the lowest at the Damas (10 \pm 16 eggs/L) (Fig. 5a).

Apart from Melen and Damas, all the other sampling points present the highest Ancylostoma sp. eggs load during the SRS (Fig. 5b). During this season, the densities vary from $75 \pm 60 \mathrm{eggs} / \mathrm{L}$ at Mokolo to 0 eggs/L at Ekounou. During the LDS, the highest load was observed at Melen $(43 \pm 73 \mathrm{eggs} / \mathrm{L})$ and the lowest at Bonamoussadi, Etougebe, Tsinga and Ekounou $(0 \pm 0$ eggs/L).

All the stations present the highest Enterobius sp. egg load during the SRS. During this season, the densities vary from $311 \pm 427 \mathrm{eggs} / \mathrm{L}$ at Mvog-betsi to $9 \pm 9 \mathrm{eggs} / \mathrm{L}$ at Ekounou. During the LDS, the highest loads are observed at the Mvog-betsi and Tsinga $(6 \pm 10$ eggs/L) and lowest at the Bonamoussadi, Etoug-ebe, Ekounou and Damas $(0 \pm 0$ eggs/L) as presented in Fig. 5c. Except for the Etoug-ebe marshy area, all the other marshy areas present the highest Trichuris sp. egg load during the SRS (Fig. 5d). During this season, the densities vary from $104 \pm 65$ eggs/L at Tsinga to $3 \pm 5$ eggs/L at Damas. During the LDS, the highest load was observed at Etoug-ebe $(240 \pm 415 \mathrm{eggs} / \mathrm{L})$ and the lowest at Bonamoussadi and Melen $(0 \pm 0$ eggs/L).

All the stations present the highest Trichostrongylus sp. egg load during the SRS. During this season, the densities vary from $88 \pm 77 \mathrm{eggs} / \mathrm{L}$ at Tsinga to $10 \pm 17 \mathrm{eggs} / \mathrm{L}$ at Damas (Fig. 5e). During the LDS, the highest load is observed at Bonamoussadi station $(26 \pm 45 \mathrm{eggs} / \mathrm{L})$ and the lowest at the Mvog-betsi and Etoug-ebe $(0 \pm 0$ eggs/L). All the stations present the highest load of Strongyloides sp. larvae during the SRS (Fig. 5f). During this season, the densities vary from $303 \pm 264$ larvae/L at Mokolo to $30 \pm 51$ larvae/L at Damas. During the LDS, the highest load is observed at the Tsinga ( $73 \pm 123$ larvae/L) and the lowest at the Etoug-ebe and Ekounou $(0 \pm 0$ larvae/L).

Seasonal variation of cestode eggs: Hymenolepis nana (A); Hymenolepis diminuta (B); Tænia sp. (C); Diphyllobothrium sp. (D) The density of the eggs of Hymenolepis nana eggs is heterogenous during various seasons. During the SRS, the densities of Hymenolepis nana vary from $501 \pm 237 \mathrm{eggs} / \mathrm{L}$ at Tsinga to $16 \pm 27$ eggs/L at Damas. During the LDS, the
Fig. 5 Seasonal variation of the density of nematode eggs
A
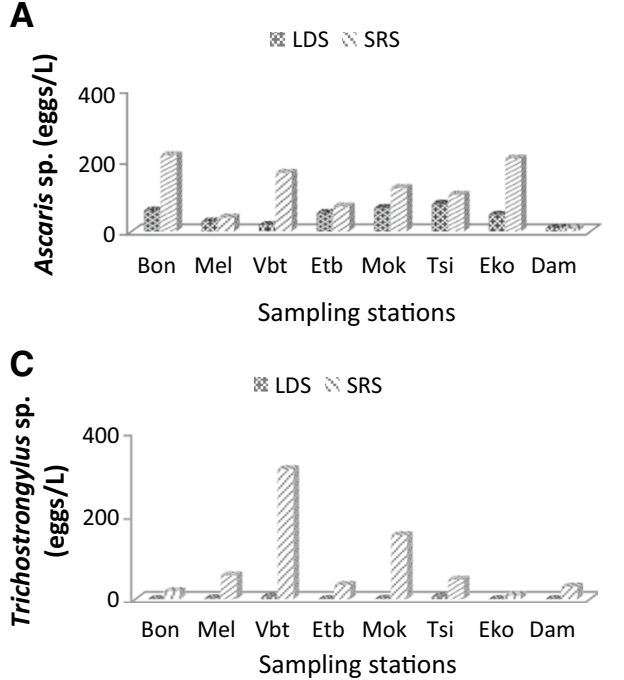

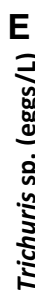

LDS $\times S R S$

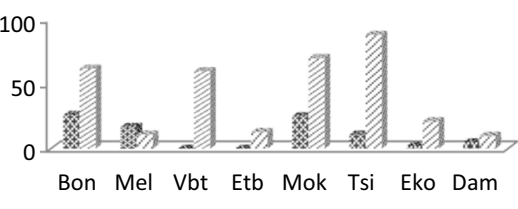

Sampling stations
B
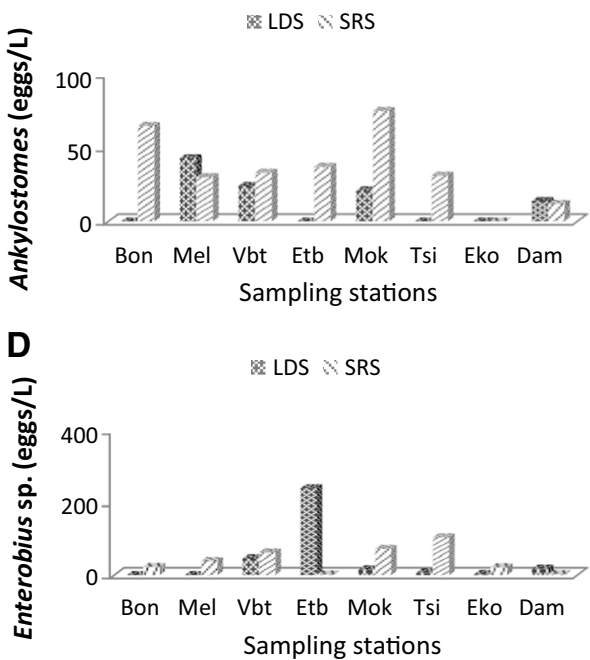

$\mathbf{F}$

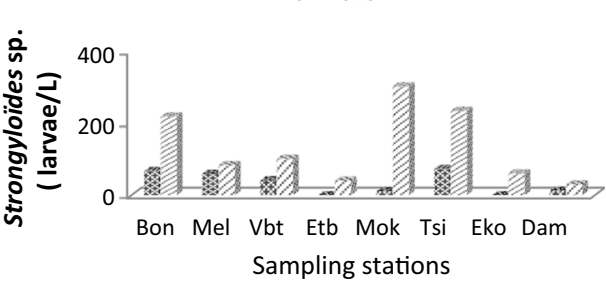


strongest load is observed at Tsinga $(204 \pm 323 \mathrm{eggs} / \mathrm{L})$ and the lowest at Damas $(10 \pm 17$ eggs/L) (Fig. 6a). During the SRS, the density of eggs of Hymenolepis diminuta varied from $46 \pm 17 \mathrm{eggs} / \mathrm{L}$ at the Mvog-betsi with $0 \pm 0 \mathrm{eggs} / \mathrm{L}$ at the Tsinga, and during the LDS, this density varies from $198 \pm 10 \mathrm{eggs} / \mathrm{L}$ at the Tsinga with $0 \pm 0 \mathrm{eggs} / \mathrm{L}$ at the Mokolo and Ekounou (Fig. 6b).

Apart from Bonamoussadi and Damas, all the other marshy areas present the highest Tania sp. egg load during the SRS. During this season, the densities vary from $118 \pm 38 \mathrm{eggs} / \mathrm{L}$ at Mokolo to $0 \pm 0 \mathrm{eggs} / \mathrm{L}$ at Ekounou. During the LDS, the highest load is also observed at Mokolo $(73 \pm 41$ eggs/L) and the lowest at the Mvog-betsi, Etougebe, Tsinga and Ekounou stations ( $0 \pm 0$ eggs/L) (Fig. 6c). At the exception of Tsinga, all the other areas present the highest Diphyllobothrium sp. egg load during the SRS (Fig. 6d). During this season, the densities vary from $87 \pm 151 \mathrm{eggs} / \mathrm{L}$ at Mvog-betsi to $3 \pm 5 \mathrm{eggs} / \mathrm{L}$ at Ekounou. During the LDS, the highest load is observed at Melen $(48 \pm 81 \mathrm{eggs} / \mathrm{L})$ and lowest at the Mvog-betsi, Etoug-ebe and Ekounou $(0 \pm 0$ egg/L).

Seasonal variation of trematodes eggs: Schistosoma (A) and Fasciola (B) At the exception of Mokolo and Ekounou, all the other areas present the highest Schistosoma sp. eggs load during the SRS. During this season, the density varies from $62 \pm 47$ eggs/L at Bonamoussadi to $5 \pm 5$ eggs/L at Ekounou. During the LDS, the highest load is observed at Mokolo $(22 \pm 27 \mathrm{eggs} / \mathrm{L})$ and the lowest at Damas $(2 \pm 4$ eggs/L) (Fig. 7a). No significant difference was observed during the seasons $(p=0.8437)$ for the biodynamic of the pathogens assessed.

The eggs of Fasciola sp. were higher in the SRS; during this season, the highest value $(59 \pm 101 \mathrm{eggs} / \mathrm{L})$ was observed at the Mokolo and the lowest value $(0 \pm 0 \mathrm{egg} / \mathrm{L})$ was observed in Damas. During the LDS, the highest value $(31 \pm 49$ eggs/L) was observed at Tsinga while the lowest values $(0 \pm 0$ eggs/L) were observed in Bonamoussadi, Etoug-ebe, Mokolo, Ekounou and Damas (Fig. 7b).

\section{Statistical analyses}

Correlations of spearman Suspended matter is significantly and positively correlated with Enterobius sp. eggs of $(r=0.642 ; p=0.004)$, with Trichostrongylus sp. eggs $(r=0.447 ; p=0.040)$, with Strongyloides sp. larvae $(r=0.452 ; p=0.039)$ and with Schistosoma sp. eggs $(r=0.452 ; p=0.039)$. Oxydability is significantly and
Fig. 6 Seasonal variation of the density of cestodes eggs

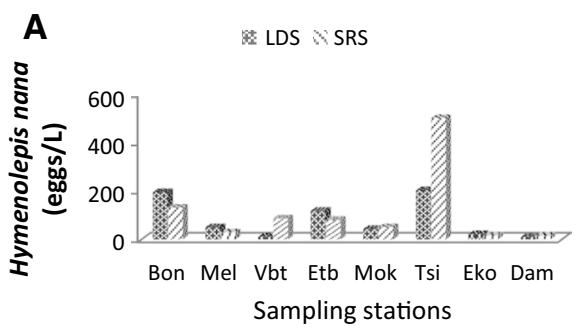

A

C

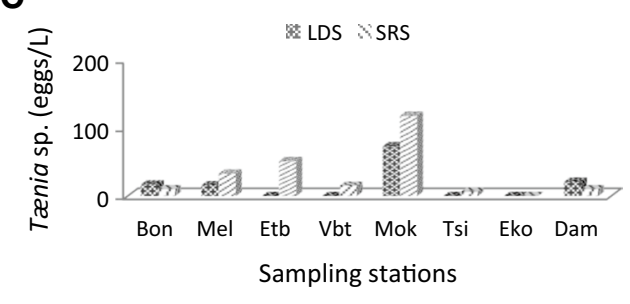

density of trematodes eggs
A

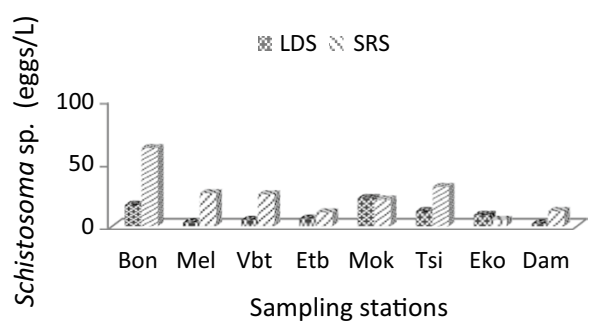

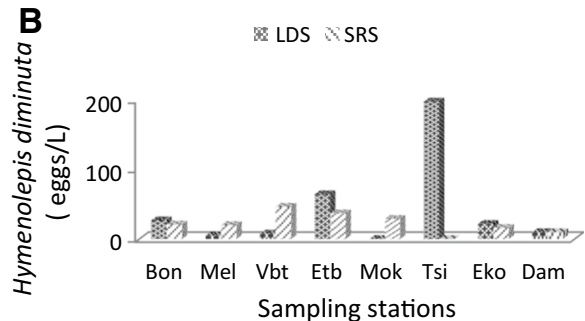

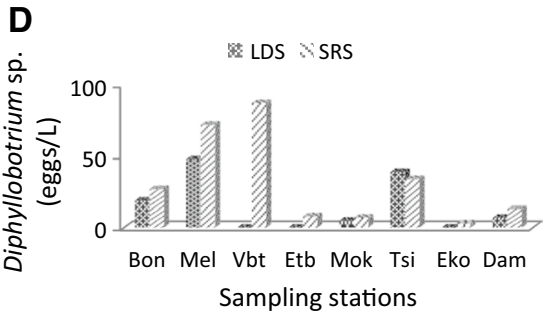

B

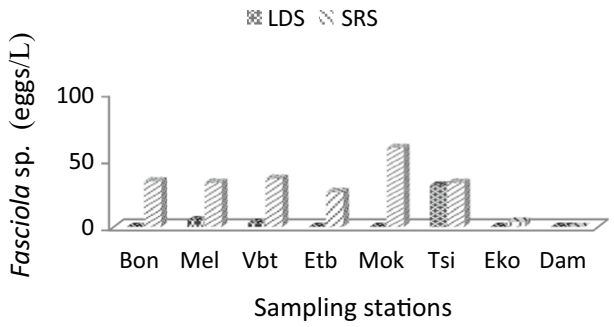


positively correlated with the eggs of Trichostrongylus sp. $(r=0.10 ; p=0.486)$, with eggs of Trichuris sp. $(r=0.458$; $p=0.031)$ and with Schistosoma sp. (0.40). Orthophosphates are significantly and positively correlated with eggs of Enterobius sp. $(r=0.190 ; p=0.241)$ and with Trichuris $(r=0.263 ; p=0.029)$; ammoniacal nitrogen is significantly and positively correlated with eggs of Ascaris sp. $(r=0.599$; $p=0.007)$, with eggs of Trichostrongylus sp. $(r=0.472$; $p=0.032)$, with eggs of Trichuris $(r=0.263, p=0.022)$ and with eggs of Schistosoma sp. $(r=0.531 ; p=0.017)$ (Table 1).

Analysis of principal components (ACP) The principal components analysis (Fig. 8) reveals distribution of all the measured parameters and sampling stations into 3 groups, according to the relationship which exists between these parameters and the stations. Group 1 presents Etoug-ebe and Mvog-betsi attesting a connection between certain chemical parameters such as electric conductivity, oxydability, ammoniacal nitrogen, dissolved oxygen and eggs of Trichuris sp., Enterobius sp. Group 2 mainly contains eggs of Tania and Diphyllobothrium which are characteristic of the Melen and Mokolo stations. Group 3 is made of Tsinga and Bonamoussadi which are among the most polluted marshy areas that present a high correlation between the highest values of temperature, orthophosphate and the eggs of Ascaris sp., Trichostrongylus sp., Hymenolepis nana, Hymenolepis diminuta, Schistosoma sp., Fasciola sp., Strongylö̈des sp. Damas and Ekounou stations which are those indicating the lowest number of parasitic elements were found do not present any relationship with the physicochemical and biological parameters.
Table 1 Correlations between some physicochemical and biological variables

\begin{tabular}{llccc}
\hline Biological parameters & \multicolumn{4}{l}{ Physicochemical variables } \\
\cline { 2 - 5 } & Suspended mater & Oxydability & $\mathrm{P}_{4}^{-}$ & $\mathrm{NH}_{4}^{+}$ \\
\hline Genera & 0.350 & -0.24 & -0.402 & $0.599^{* *}$ \\
Ascaris sp. & $0.642^{* *}$ & -0.270 & $0.190^{*}$ & $-0.780^{* *}$ \\
Enterobius sp. & $0.447^{* *}$ & $0.10^{*}$ & 0.268 & $0.472^{*}$ \\
Trichostrongylus sp. & $0.452^{*}$ & -0.90 & 0.396 & $-0.529^{*}$ \\
Strongylö̈des sp. & $0.452^{*}$ & 0.40 & -0.325 & $0.531^{*}$ \\
Schistosoma sp. & 0.015 & $0.458^{*}$ & $0.263^{*}$ & 0.350 \\
Trichuris sp. & & & & \\
\hline
\end{tabular}

*Significant correlation to the threshold 5\%, **significant correlation to the threshold $1 \%$

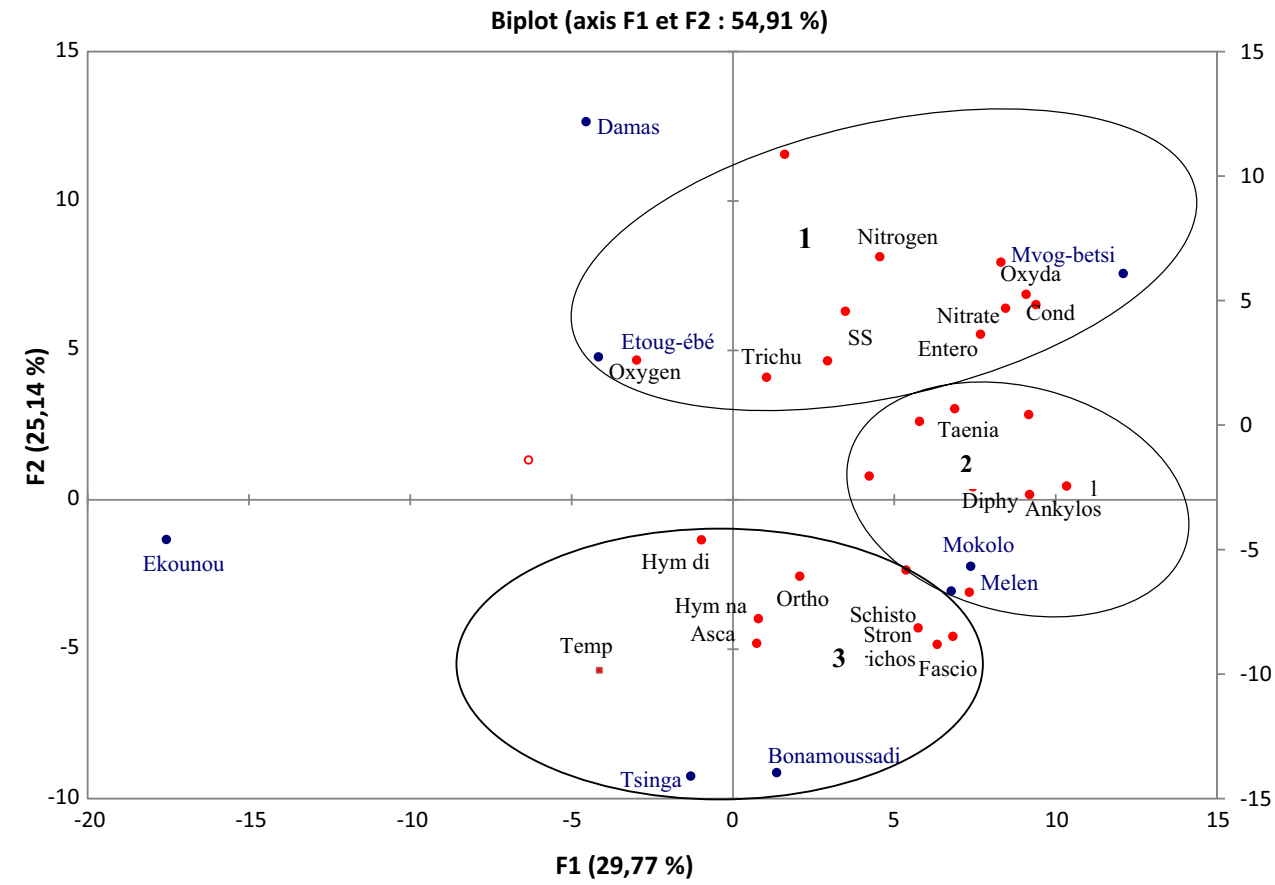

Fig. 8 Principal component analysis presenting the specificity of each sampling station and the connections between the various measured parameters 


\section{Discussion}

The average value of electric conductivity $(566.16 \pm 119.91) \mu \mathrm{S} / \mathrm{cm}$ recorded from this study is characteristic of averagely mineralized water. The highest value of electric conductivity $(1080.33 \pm 303.27) \mu \mathrm{S} / \mathrm{cm}$ obtained at Mvog-betsi station could explain clearly that the main part of the dissolved ionizable substances which enrich this medium results from the mineralization of the organic matter as a result of human activities (Nola et al. 2006).

The low values of oxygenation obtained could represent organic pollution, and the values lower than $30 \%$ obtained in LDS and those lower than 50\% obtained in SRS are characteristic of very polluted ecosystems (Rodier 2009). The increase in the rate of oxygenation observed in the rainy season could be due to the phenomenon of turbulence and mixing of water, supported by the rains and winds (Rodier 2009). The average value of oxydability $\left(12.86 \pm 16.56 \mathrm{mg} / \mathrm{L}\right.$ of $\left.\mathrm{KMnO}_{4}\right)$ obtained at Mokolo is higher than the standards recommended for surface water quality which is less than $10 \mathrm{mg} / \mathrm{L}$ of $\mathrm{KMnO}_{4}$. This could be explained by a significant anthropogenic activity at this point, as materialized by several artisanal activities and precarious sanitary conditions.

The average values of nitrate $\left(5.48 \pm 1.60 \mathrm{NO}_{3}^{-} \mathrm{mg} / \mathrm{L}\right)$ and ammoniacal nitrogen of the sampled water $\left(0.32 \pm 0.07 \mathrm{mg} / \mathrm{L}\right.$ of $\left.\mathrm{NH}_{4}{ }^{+}\right)$are, respectively, higher than the normal values of $3 \mathrm{mg} / \mathrm{L}$ for nitrate and $0.1 \mathrm{mg} / \mathrm{L}$ for ammoniacal nitrogen and translated by this organic pollution (Rodier 2009). The high value of nitrate $(11.06 \pm 3.57$ $\mathrm{NO}_{3}^{-} \mathrm{mg} / \mathrm{L}$ ) is obtained in LDS at Mvog-betsi, by the presence of biodegradable organic matter.

The average orthophosphate content of the sampled water $\left(5.77 \pm 2.40 \mathrm{mg} / \mathrm{L}\right.$ of $\left.\mathrm{PO}_{4}^{3-}\right)$ is higher than the values $\left(2.4 \mathrm{mg} / \mathrm{L}\right.$ of $\mathrm{PO}_{4}^{3-}$ ) recommended by the United Nations for Food and Agriculture (FAO 2003). This high value could be explained by the arrival of domestic wastewater that is rich in detergent solutions, of water effluents coming from latrines or by the scrubbing of the cultivated grounds containing phosphate-enriched fertilizers. According to Rodier (2009), the presence of phosphates in water is related to the decomposition of the organic matter.

The biological analysis of the water samples of the various stations reveals variable densities of intestinal helminths eggs and larvae, with 56\% nematodes, $34 \%$ cestodes and $10 \%$ of trematodes. Similar observations ( $86 \%$ of nematodes, $10 \%$ cestodes and $4 \%$ of trematodes) had been presented by Nsom et al. (2010) on the wastewater of Maamoro in Morocco Council. The monthly values obtained oscillate between 0 and 501 parasites/L, with 0-218 parasites/L for Bonamoussadi, 0-82 agents/L for
Melen, 0-311 agents/L for Mvog-betsi, 0-240 agents/L for Etoug-ebe, 0-303 agents/L for Mokolo, 0-501 agents/L for Tsinga, 0-205 agents/L for Ekounou and 0-30 agents/L for Damas. The presence of helminths eggs and larvae in these waters testify the law of environmental quality of urban water systems. According to Rodier (2009), the presence of the intestinal parasites in marshy zones is related to a contamination of fecal origin. Moreover, according to the French Institute of Tropical Medicine (2004), the prevalence of helminthiases is very high in the marshes and is a function of the climatic, socioeconomic and demographic factors. These observations join those of Kengne et al. (2002) working in some stream detected a pollution of fecal origin.

Seasonally, the highest densities of helminths eggs and larvae were observed in SRS. This could be explained by organic matter coming from toilets and households. Similar observations had been made by Kouam et al. (2010). In this light, WHO (1989) announces that the abundance of helminths eggs in the rainy season is due to the conditions of temperature, moisture, oxygen and solar radiation which is favorable to their embryonic (Ajeagah et al. 2014). The eggs and larvae of helminths can resist up to two years between -30 and $+30{ }^{\circ} \mathrm{C}$ and are sensitive to heat. In the same order, the Institute of Tropical Medicine declares that the high precipitations observed in the rainy season lead to soil humidification, thus facilitating the maturation and the dissemination of helminths eggs and larvae having as consequence the increase in the prevalence rate (IFMT 2004).

On the spatiotemporal plan level, Tsinga station has the highest density of parasitic agents $(958 \pm 888$ agents/L), this could be explained by the presence of a market and of a stadium in the surroundings, and thus, the absence of toilets causes the various users to defecate in the macrophytes which are around the marshy area. The Mokolo and Bonamoussadi closely follow Tsinga with, respectively, $710 \pm 700$ agents/L and $700 \pm 588$ agents/L. These high loads could be explained by the presence of toilets along the river banks which borders the Bonamoussadi area and also by arrival of the effluents coming from the University Hospital Complex. According to Ajeagah et al. (2014), the effluents of hospitals contain many forms of helminths that could easily be released toward the marshy area (Aghaindum et al. 2016). The low value of parasitic agents observed at the Damas compared to the other stations could be explained by the long distance between this station and the dwelling houses. The high distribution of Ascaris sp. eggs could be explained by their high resistance in the environment, due to the presence of a thick membrane, and the eggs can last a long time in the external medium (Bouhoum et al. 1997). The low representativeness of Schistosoma sp. eggs is due to their very fragile nature in polluted environment. 
High correlations were observed between suspended mater and organic matter and between suspended matter, organic matter and parasitic elements. Suspended solids and the organic matter play a significant role in the dissemination of the helminths eggs and larvae in the environment by their association into ionic, covalent and hydrogen bonding (Aghaindum et al. 2016).

\section{Conclusion}

This study made it possible to evaluate the physicochemical quality and to characterize the forms of resistance of the helminths in some marshy zones of Yaounde. The studying areas present anthropic pollution with an increase in biodegradable organic and fecal matter. The biological analysis reveals the presence of helminths eggs and larvae of which 56\% are nematodes (Ascaris sp., Enterobius sp., Ankylostomes sp., Strongylö̈des sp., Trichostrongylus sp., Trichuris sp.); $34 \%$ are cestodes (Tania sp., Hymenolepis nana, Hymenolepis diminuta, Diphyllobothrium sp.); $10 \%$ are trematodes (Fasciola sp., Schistosoma sp.). The highest densities of eggs and larvae were recorded during the short rainy season. Positive correlations were noted between the biological and physicochemical parameters of the medium. The majority of the gardening crops and fruits in Yaounde come from marshy areas, and the presence of pathogenic agents in these areas renders these waters unsuitable for the irrigation of crops and their usage in domestic chores.

Open Access This article is distributed under the terms of the Creative Commons Attribution 4.0 International License (http://creativeco mmons.org/licenses/by/4.0/), which permits unrestricted use, distribution, and reproduction in any medium, provided you give appropriate credit to the original author(s) and the source, provide a link to the Creative Commons license, and indicate if changes were made.

\section{References}

Aghaindum AG, Atud AQ, Moïse N (2016) Bioqualité Des Formes De Dissémination Des Protozoaires Flagellés Entériques Dans Les Eaux Souterraines (Sources Et Puits) En Zone Anthropisée (Yaoundé-Cameroun). Eur Sci J 33(12):1857-7431

Ajeagah GA, Foto Menbohan S, Talom SN, Ntwong MM, Tombi J, Nola M, Njine T (2014) Physicochemical and dynamic property of abundance of the intestinal forms of dissemination of the helminths in worn water and from surface in Yaounde (Cameroun). Eur J Sci Res 120:44-63

Bouhoum K, Amahmid O, Habbariet KH, Schwartzbrod J (1997) Devenir des œufs d'helminthes et kystes de protozoaires dans un canal à ciel ouvert alimenté par les eaux usées da Marrakech (Maroc). Rev Sci Eau 10(2):217-232

FAO (United Nations for the Food and Agriculture) (2003) The irrigation with treated worn water: instruction manual. FAO Irrigation and Drainage, $\mathrm{p} 65$

IFMT (Institut Francophone de Médecine Tropicale) (2004) Rapport du séminaire sur les helminthiases transmises par le sol, pp 3-6

Kengne IM, Endamana D, Soh L, Nya J (2002) Re-use of the water used for urban agriculture in the town of Yaounde. In: Visit of study and international workshop on the re-use of the water used in urban agriculture: a challenge for the municipalities in West Africa. Final report/ratio, Ouagadougou - Burkina Faso, pp $116-123$

Kouam KenmogneG, Rosillon F, Mpakam HG, Nono A (2010) Enjeux sanitaires, socio-économiques et environnementaux liés à la réutilisation des eaux usées dans le maraîchage urbain: cas du bassin versant de l'Abiergué (Yaoundé-Cameroun). Vertigo la Revue Electronique en Sciences de l'Environnement 10(2):57-60

Nola M, Njine T, Kemka N, Zébazé Togouet SH, Foto Menbohan S, Monkiedje A, Servais P, Messouli M, Boutin CL (2006) Total retention of staphylococci and coliforms during wastewater percolation through equatorial soil in Africa exchange: the role of the soil column near soil surface and that closely above groundwater table. Water Air Soil Pollut 171:253-271

Nsom Z, Belghyti D, Lyagoubi M (2010) Etude parasitologique (œufs d'helminthes) des eaux usées brutes de la commune urbaine de Maâmora à Kénitra (Maroc). J Européen d'Hydrologie 34(2):245-250

PNLSHI (National Programme of Fight against Intestinal Schistosomiasis and Helminthiases in Cameroun) (2010) Strategic plan 2005-2010, p 92

Rodier J (2009) L'analyse de l'eau, 9th edn. Dunod, Paris, p 1579

Tchuem Tchuemté LA, Southgate VR, Vercruysse J (2001) La bilharziose et les géohelminthiases dans l'Arrondissement de Makénéné, province du Centre, Cameroun. Le Bulletin de Liaison et de Documentation de l'OCEAC 34:19-22

WHO (1989) The use of the water used in agriculture and aquiculture: recommendations with medical aimings. Report/ratio of a scientific group of WHO, Report N 778. Geneva, p 29

WHO (1994) Boards for the diagnosis of the intestinal parasites. Geneva, p 29

WHO (1999) Report/ratio on health in the world, for a real change. World Health Organization, Geneva, p 47

Youssef EG, Driss B (2007) Charge parasitaire des eaux usées brutes de la ville de Kénitra (Maroc). J Européen d'Hydrologie 8(3):123-145

Publisher's Note Springer Nature remains neutral with regard to jurisdictional claims in published maps and institutional affiliations. 